\title{
STRATEGI PENGEMBANGAN SDM SEBAGAI PERSIAPAN MEMBANGUN DESTINASI WISATA CURUG ANGKREK, KP. CIMUNCANG, DESA KARANGNUNGGAL, KABUPATEN TASIKMALAYA
}

\author{
Dede Andi ${ }^{1}$, Melda Wiguna ${ }^{2}$, Muhamad Abid ${ }^{3}$, Abdul Rahman Safiih ${ }^{4}$, \\ Imbron $^{5}$ \\ Universitas Pamulang \\ Email: dosen02463@unpam.ac.id
}

\begin{abstract}
The purpose of Community Service Activities is to carry out one of the higher education Tri Darma. It is hoped that with this community service, the existence of universities can make a major contribution to the development and application of science to the community. The method used in this Community Service is in the form of counseling and coaching in the form of delivering material in the form of presentations. The results of community service that are obtained are the increase in knowledge and the role of human resources as the motor of the tourism industry, creators of tourism industry products, and as a determinant of the competitiveness of the tourism industry. This activity is expected to be able to give new enthusiasm, because as it is known that the tourism sector in Indonesia still plays a very important role in supporting national development as well as a very strategic factor to increase people's income and foreign exchange.
\end{abstract}

Keywords: Human Resource Development, Tourist Attraction.

\begin{abstract}
Abstrak
Tujuan dari Kegiatan Pengabdian Kepada Masyarakat adalah untuk melaksanakan salah satu Tri Darma Perguruan Tinggi. Selain itu diharapkan dengan pengabdian kepada masyarakat tersebut keberadaan perguruan tinggi dapat memberikan kontribusi besar kepada pengembangan dan penerapan keilmuan kepada masyarakat. Metode yang digunakan pada Pengabdian Kepada Masyarakat ini berupa penyuluhan dan pembinaan berupa penyampaian materi dalam bentuk presentasi. Hasil pengabdian masyarakat yang diperoleh adalah bertambahnya keilmuan dan peran SDM sebagai motor penggerak industri pariwisata, pencipta produk industri pariwisata, dan sebagai penentu daya saing industri pariwisata. Ilmu yang diperoleh pada Pengabdian Masyarakat kali ini diharapkan mampu memberikan semangat baru bagi kita karena sebagaimana diketahui bahwa sektor pariwisata di Indonesia masih menduduki peranan yang sangat penting dalam menunjang pembangunan nasional sekaligus merupakan salah satu faktor yang sangat strategis untuk meningkatkan pendapatan masyarakat dan devisa negara.
\end{abstract}

Kata Kunci: Pengembangan SDM, Destinasi Wisata. 


\section{A. PENDAHULUAN}

Terletak di kampung cimuncang RT 009, RW 10, sebuah kepunduhan yang berada di desa karangnunggal, kecamatan Karangnunggal, kabupaten Tasikmalaya. Wisata alam curug angkrek yang di gadang-gadang sebagai destinasi desa karangnunggal. Dimana objek wisata alam yang belum lama ini di buka aksesnya oleh pemerintah desa, kendati pun baru tempat tersebut sudah ramai di kunjungi wisatawan.

Meskipun untuk mencapai keindahan air terjun yang sangat menakjubkan setinggi 16 meter itu para wisatawan harus rela melalui sebagian jalan tanah dan bebatuan kurang lebih selama 1 jam dari pusat kecamatan karangnunggal, tetapi hal tersebut tidak mengurangi minat wisatawan untuk berkunjung. Pengunjung tidak hanya dari daerah saja, wisatawan asing pun mulai melirik dan berdatangan. Mayoritas pengunjung sementara ini adalah kaum muda-mudi dan pencinta alam.

Keberadaan SDM berperanan penting dalam pengembangan pariwisata. SDM pariwisata mencakup wisatawan/pelaku wisata (tourist) atau sebagai pekerja (employment). Peran SDM sebagai pekerja dapat berupa SDM di lembaga pemerintah, SDM yang bertindak sebagai pengusaha (wirausaha) yang berperan dalam menentukan kepuasan dan kualitas para pekerja, para pakar dan profesional yang turut berperan dalam mengamati, mengendalikan dan meningkatkan kualitas kepariwisataan serta yang tidak kalah pentingnya masyarakat di sekitar kawasan wisata yang bukan termasuk ke dalam kategori di atas, namun turut menentukan kenyamanan, kepuasan para wisatawan yang berkunjung ke kawasan tersebut.

\section{B. METODE PELAKSANAAN}

Metode yang digunakan pada Pengabdian Kepada Masyarakat ini yaitu penyuluhan dan pembinaan berupa penyampaian materi dalam bentuk presentasi. Serta membuat kerangka pemecahan masalah. Kerangka pemecahan masalah merupakan serangkaian prosedur dan langkah-langkah dalam penelitian yang bertujuan untuk mendapatkan tahapan yang terstruktur secara sistematis, sehingga penelitian dapat dilakukan dengan efektif dan efisien. Adapun kerangka pemecahan masalahnya adalah : Perumusan Masalah, Perencanaan Kegiatan, Pemilihan Teknik dan Materi, Pemilihan Peserta Pembinaan, Pelaksanaan Pembinaan dan Penyuluhan dan Membantu Memecahkan Masalah Pada Masyarakat:

\section{HASIL DAN PEMBAHASAN}

Kegiatan penyuluan dan pembinaan untuk menerapkan strategi mengembangkan sumber daya manusia dalam membangun Destinasi Wisata Curug Angkrek Desa Karangnunggal Kabupaten Tasikmalaya yang digadang-gadang sebagai destinasi wisata Desa Karangnunggal. Kegiatan penyuluan dan pembinaa ini dimulai dengan sambutan dari ketua RT setempat yaitu Bpk. Suhendar dan ketua karang taruna dengan Bpk. Iwan, mereka sangat antusias dengan adanya kegiatan ini: 

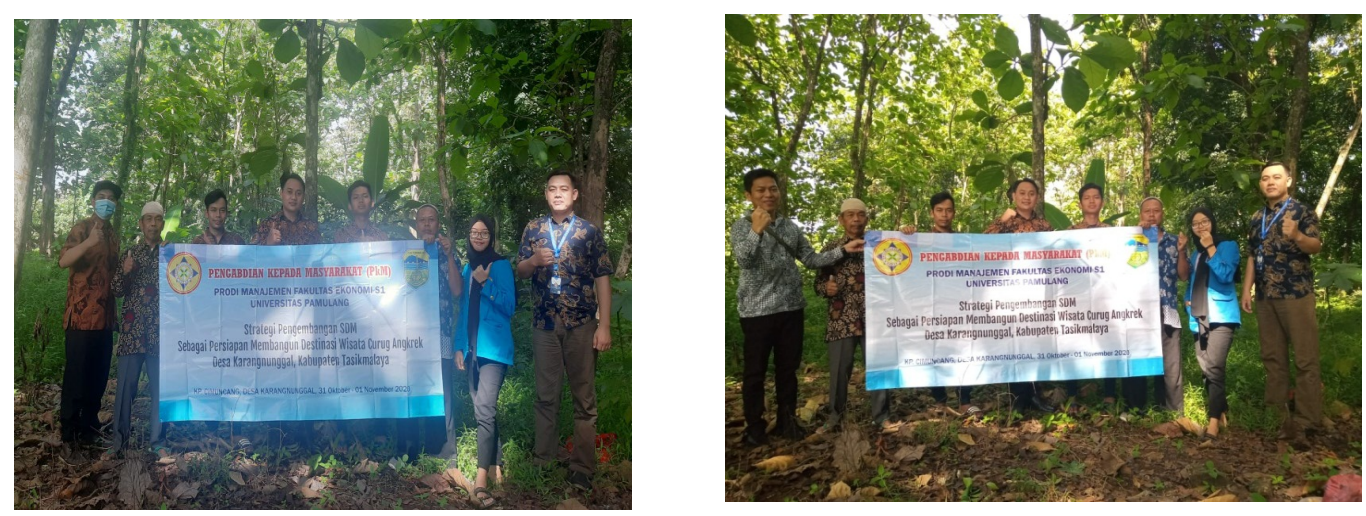

Gambar 1.1 Photo Tim Pengabdian Kepada Masyarakat (PkM)

Disampaikan oleh Bpk Suhendar selaku ketua RT agar masyarakat sekitar diberi dan dibekali pemahaman khususnya terkait potensi dari wisata curug angkrek yang berpotensi mengembangkan taraf hidup masyarakat sekitar. Sendada dengan yang disampaikan ketua RT, dari ketua pengabdian yang di ketuai oleh Dede Andi, S.E., M.M. menyampaikan terimakasih atas antusias warga setempat dalam hal penyampaian materi dan penyuluhan yang dilakukan oleh dosen-dosen dari Universitas Pamulang, diharapkan agar kegitan ini dapat berkesinambungan sehingga akan membantu masyarakat berbagi informasi dan edukasi tentang potensi potensi di sekitar.

Dalam kegiatan tersebut ada beberapa perubahan yang dilihat dari masyarakat khususnya peserta yang hadir begitu antusias dan bersemangat sehingga memotivasi warga setempat untuk mengembangkan diri, mencari inovasi inovasi baru terkait destinasi wisata curug angkrek, hal tersebut bisa kita lihat ari antusias warga baik yang bertanya maupun menaggapi materi yang disampaikan.

Berdasarkan wawancara, tanya jawab dan pengamatan langsung selama kegiatan berlangsung, kegiatan pengabdian pada masyarakat ini memberikan hasil sebagai berikut :

1) Meningkatnya pengetahuan dan pemahaman masyarakat sekitar tentang pengembangan SDM sebagai persiapan membangun destinasi wisata curug angkrek

2) Meningkatnya semangat, motivasi dan inovasi masyarakat sekitar untuk lebih mendalami tentang potensi potensi yang akan didapat dari destinasi wisata curug angkrek

\section{KESIMPULAN DAN SARAN}

\section{Kesimpulan}

Pelaksanaan kegiatan Pengabdian Kepada Masyarakat oleh Lembaga Penelitian dan Pengabdian Masyarakat (LPPM) Universitas Pamulang yang dilakukan oleh dosen-dosen program studi Manajemen telah berjalan dengan lancar dan mendapat sambutan hangat dari tempat pelaksanaan kegiatan ini yaitu dilakukan pada warga sekitar daerah wisata curug angkrek Desa Karangnunggal Kabupaten Tasikmalaya dengan tema : Strategi Pengembangan SDM Sebagai Persiapan Membangun Destinasi Wisata Curug Angkrek, Kp. Cimuncang, Desa Karangnunggal, Kabupaten Tasikmalaya

Harapan kami dengan pengabdian ini dapat membuka wawasan dari masyarakat tentang pentingnya pengembangan SDM dan strategi guna persiapan membangun destinasi wisata. Materi yang kami berikan yaitu penyuluhan dan pembinaan sehingga dapat membantu dan meningkatkan motivasi masyarakat baik dalam tingkat keilmuan, pengetahuan dan keperibadian yang lebih unggul yang akan sangat bermanfaat dalam kehidupan masyarakat sekitar. 
Saran

Mengingat besarnya manfaat kegiatan pengabdian pada masyarakat ini, maka selanjutnya perlu.

1. Mengadakan penyuluhan dan pembinaan serupa pada masyarakat lain di Kecamatan yang lain, dengan materi yang sama.

2. Adanya kesinambungan program pasca kegiatan pengabdian ini sehingga masyarakat benar-benar dapat termotivasi untuk kedepannya guna persiapan membangun destinasi wisata curug angkrek

\section{DAFTAR PUSTAKA}

Dewi, I.K., Ahyani., Sudarso, A.P., Liawati., \& Widowati. (2020). Pengelolaan Hasil Pertanian Dalam Meningkatkan Harga Jual Pada Petani Di Desa Cicalengka Kecamatan Pagedangan Kabupaten Tangerang - Banten. DEDIKASI PKM. 1 (3).

Dumilah, R., Sunarto, A., Solihin, D., \& Maulida, H. (2020). Pelatihan Pemanfaatan Media Sosial Untuk Promosi Usaha Atau Bisnis Bagi Siswa. DEDIKASI PKM, 1(1), 26-33.

Hasibuan, Malayu S.P. (2014). Manajemen Sumber Daya Manusia. Jakarta: Bumi Aksara

Kementrian Pariwisata. (2016). Laporan Kinerja Kementerian Pariwisata tahun 2015. Jakarta.

Kemenpar. (2012). Pedoman Kelompok Sadar Wisata. Jakarta: Kementrian Pariwisata dan Ekonomi Kreatif

Mardiana, S., Supriyatna, W., Hasanah, Y. M., Zakaria., \& Indirasari, I. (2010). Optimalisasi Anggaran Keuangan Di Masa Pandemi Pada Desa Cicalengka Kabupaten Pagedangan Tangerang. DEDIKASI PKM. 1 (3).

Mudrajad. (2004). Otonomi daerah dan pembangunan daerah. Jakarta: Erlangga.

Pujileksono, Sugeng. (2015). Metode Penelitian Komunikasi Kualitatif. Malang: Kelompok Intrans Publishing.

Qurbani, D., Mardiana, S., \& Nugroho, R. D. (2020). Meningkatkan Minat Dan Potensi Generasi Milenial Khususnya Siswa-Siswi SMK Darussalam Untuk Memulai Bisnis Online Dengan Sistem Dropship. DEDIKASI PKM. 1 (3).

Rahman, M.R. (2019). Pentingnya Mengangkat Daya Saing SDM Sektor Pariwisata, https://www.antaranews.com/berita/1032440/pentingnya-mengangkat-daya-saing-sdmsektor-pariwisata, diakses pada 01 September 2020

Sari, R., Suryani, N. L., Setiawan, R., Darmadi., \& Susanto, N. (2020). PENGELOLAAN SUMBER DAYA MANUSIA DALAM MENINGKATKAN PRODUKTIVITAS PADA UKM KELURAHAN PAGEDANGAN KABUPATEN TANGGERANGBANTEN. DEDIKASI PKM. 1 (3).

Sedarmayanti (2014). Membangun \& mengembangkan kebudayaan dan industri pariwisata: Bunga rampai tulisan pariwisata. Bandung: PT Refika Aditama.

Solihin, D., Susanto, N., Setiawan, R., Ahyani, \& Darmadi. (2020). Penerapan Strategi Pemasaran Sebagai Upaya Meningkatkan Usaha Kecil Dan Menengah Warga Di Kelurahan Paninggilan Utara Ciledug. ABDI LAKSANA, 1(3), 351-355. 
Solihin, D., Prasetiyani, D., Sari, A. R., Sugiarti, E., \& Sunardi, D. (2020). Pemanfaatan Botol Bekas Sebagai Penyaring Air Bersih Sederhana Bagi Warga Desa Cicalengka Kecamatan Pagedangan Kabupaten Tangerang. DEDIKASI PKM, 1(3), 98-102.

Soekidjo. (2000). Anatomi Pariwisata Memahami Pariwisata sebagai Systemic Linkage. Jakarta: Gramedia Pustaka Utama.Kuncoro,

Sunaryo, B., (2013). Kebijakan Pembangunan Destinasi Pariwisata Konsep dan Aplikasinya di Indonesia. Yogyakarta: Gava Media. 